\title{
SULFUR-DOPED-TITANIA COATED ON MAGNETITE AS MAGNETICALLY RECOVERABLE PHOTOCATALYST FOR THE UV-VISIBLE LIGHT-ASSISTED-DEGRADATION OF CONGO RED SOLUTION
}

\author{
E.S. Kunarti ${ }^{\bowtie}$, I. Kartini, M.I.D. Mardjan and E.H. Prameswari \\ Department of Chemistry, Universitas Gadjah Mada, Sekip Utara, Yogyakarta 55281, Indonesia \\ ${ }^{\square}$ Corresponding Author: eko_kunarti@ugm.ac.id
}

\begin{abstract}
Novel magnetically recoverable photocatalysts of sulfur-doped-titania coated on magnetite, $\mathrm{Fe}_{3} \mathrm{O}_{4} / \mathrm{TiO}_{2}-\mathrm{S}$, were synthesized through the sono-coprecipitation method involving $\mathrm{Fe}_{3} \mathrm{O}_{4}$, titanium tetraisopropoxide and thiourea as the sulfur source. The synthesized photocatalysts were then employed in the photodegradation of Congo red at pH 5 for $90 \mathrm{~min}$. The results showed that $\mathrm{Fe}_{3} \mathrm{O}_{4} / \mathrm{TiO}_{2}-\mathrm{S}$ photocatalysts display very good photodegradation activity under UV light illumination. In addition, the sulfur doping strategy allows us to conduct the photodegradation of Congo red under visible light irradiation since it may reduce the photocatalyst bandgap energy and shift the wavelength to the visible light region. Moreover, the $\mathrm{Fe}_{3} \mathrm{O}_{4} / \mathrm{TiO}_{2}-\mathrm{S} 5 \%$ and $10 \%$ photocatalysts demonstrate excellent visible lightdriven-photocatalytic degradation of Congo red with the photoactivity of $96.25 \%$ and $98.75 \%$, respectively.

Keywords: $\mathrm{Fe}_{3} \mathrm{O}_{4} / \mathrm{TiO}_{2}-\mathrm{S}$, Magnetic Photocatalyst, Photodegradation, Congo Red, Visible Light.
\end{abstract}

RASĀYAN J. Chem., Vol. 14, No.2, 2021

\section{INTRODUCTION}

Water pollution remains the environmental global problem. The rapid growth of the human population and chemical industries may increase the release of dangerous contaminants to the aquatic environment. Not only improve the environmental burden, but water pollution may also give various severe health effects on humans. In this context, industrial dyes such as Congo red are relatively stable and, hence, cannot be easily degraded using conventional wastewater treatments. Among various technologies, photocatalysis has received considerable attention due to its effectiveness in the removal of harmful dyes from the environment.

In recent years, $\mathrm{TiO}_{2}$ photocatalysts are widely used in water purification, as they are ideal for the degradation of organic and inorganic pollutants. ${ }^{1-4}$ The physicochemical properties of $\mathrm{TiO}_{2}$ semiconductors, such as high photoactivity, low toxicity, and relatively inexpensive, make $\mathrm{TiO}_{2}$ be attractive photocatalyst used for environmental remediation. ${ }^{5}$ However, its application as a photocatalyst, un-modified $\mathrm{TiO}_{2}$ is reported less efficient because the material is only active under exposure to ultraviolet light. ${ }^{6}$

The current challenge in the photodegradation technique is the exploitation of sunlight covering UV and visible light spectrum. In this case, the photo-response of $\mathrm{TiO}_{2}$ can be improved in the visible light area. The improvement of photocatalytic activity can be performed by doping or inserting impurities into the semiconductor material with metal elements ${ }^{7,8}$ or non-metal elements. ${ }^{9,10}$ These elements can generate a new state or energy level between the valence band and the conduction band and act as electron donors or acceptors that cause absorption in the visible light region. ${ }^{11}$ The doping of $\mathrm{TiO}_{2}$ with metal elements, however, has several disadvantages, such as the increase of hole and electron recombination and low thermal stability. ${ }^{12}$ Recently, several studies demonstrated that nonmetal doping can enhance the response of $\mathrm{TiO}_{2}$ to visible light. ${ }^{13}$ Sulfur is a non-metallic element commonly used as a $\mathrm{TiO}_{2}$ dopant, which can narrow the bandgap energy of the photocatalysts. In addition, sulfur has high stability when doped into $\mathrm{TiO}_{2}{ }^{9}$

From the practical point of view, the separation of the catalyst after the wastewater treatment is difficult and may increase the operational cost. The strategy to address this separation problem is by developing the

Rasayan J. Chem., 14(2), 1199-1207(2021)

http://dx.doi.org/10.31788/ RJC.2021.1426304

This work is licensed under a CC BY 4.0 license. 
RASĀYAN J. Chem.

Vol. 14 | No. 2 |1199-1207| April - June | 2021

magnetically separable photocatalyst, where the photocatalyst may be easily recovered using the external magnet. Previous studies have introduced the magnetic property to the various photocatalysts by coating the catalysts on magnetite. ${ }^{4,14-18}$ In this study, we report herein the development of novel sulfur-dopedtitania coated on magnetite $\left(\mathrm{Fe}_{3} \mathrm{O}_{4} / \mathrm{TiO}_{2}-\mathrm{S}\right)$. The synthesized magnetically recoverable photocatalysts will be employed in the photodegradation of Congo red dye under the illumination of both UV and visible light.

\section{Material and Methods}

\section{EXPERIMENTAL}

The materials used in this study were chemicals with pro-analysis qualities and purchased from Merck including $\mathrm{FeCl}_{3} .6 \mathrm{H}_{2} \mathrm{O}, \quad \mathrm{FeSO}_{4} .7 \mathrm{H}_{2} \mathrm{O}, \quad \mathrm{NaOH}, \quad \mathrm{NH}_{4} \mathrm{OH}, \quad\left(\mathrm{NH}_{4}\right)_{2} \mathrm{SO}_{4}$, ethanol (96\%), titanium tetraisopropoxide and thiourea. Some materials with the technical grade, such as sodium citrate, Congo red, and deionized water, were also utilized. All chemicals were used without further purification. The equipment employed in this research were X-Ray Diffractometer (XRD, Shimadzu XRD 6000), Specular Reflectance UV-Visible Spectrometer (SRUV, UV 1700 Pharmaspec UV-Vis Spectrophotometer Specular), Vibrating Sample Magnetometer (VSM, Oxford VSM 1.2H), Transmission Electron Microscope (TEM, JEOL-1400 $120 \mathrm{kV}$ ), and Scanning Electron Microscope with Energy Dispersive X-Ray (SEMEDX, JEOL JSM-651OLA).

\section{Preparation of Photocatalysts \\ Preparation of $\mathrm{Fe}_{3} \mathrm{O}_{4}$}

Into the solution of $\mathrm{FeCl}_{3} \cdot 6 \mathrm{H}_{2} \mathrm{O}(540 \mathrm{mg})$ and $\mathrm{FeSO}_{4} .7 \mathrm{H}_{2} \mathrm{O}(280 \mathrm{mg})$ in $100 \mathrm{~mL}$ of deionized water, was added dropwise $25 \%$ of $\mathrm{NH}_{4} \mathrm{OH}$ solution under sonication. After the precipitation of $\mathrm{Fe}_{3} \mathrm{O}_{4}$, the aqueous solution of sodium citrate $(0.5 \mathrm{M})$ was then introduced to the mixture and the sonication was continued for $10 \mathrm{~min}$. The obtained precipitate was separated by an external magnetic bar, washed with distilled water until $\mathrm{pH} 7$ and then dried at $100^{\circ} \mathrm{C}$ for $1 \mathrm{~h}$.

\section{Preparation of $\mathrm{Fe}_{3} \mathrm{O}_{4} / \mathrm{TiO}_{2}$}

The $\mathrm{Fe}_{3} \mathrm{O}_{4}$ particles $(116 \mathrm{mg}),\left(\mathrm{NH}_{4}\right)_{2} \mathrm{SO}_{4}(100 \mathrm{mg})$ and $\mathrm{TiO}_{2}(17,5 \mathrm{mg})$ were suspended in $20 \mathrm{~mL}$ of ethanol $96 \%$. The suspension was sonicated for $10 \mathrm{~min}$, and then added with titanium tetraisopropoxide $(1,5 \mathrm{~mL})$ and distilled water $(1.7 \mathrm{~mL})$. The sonication was carried out for $3 \mathrm{~h}$. The external magnetic bar was used to separate the precipitate from the mixture. The magnetite precipitate was then washed until neutral and calcined at $500^{\circ} \mathrm{C}$ for $3 \mathrm{~h}$. The same procedure was conducted to produce $\mathrm{Fe}_{3} \mathrm{O}_{4}: \mathrm{TiO}_{2}$ with a different molar ratio of $1: 1,3: 1,5: 1,10: 1$, and $15: 1$.

\section{Preparation of $\mathrm{Fe}_{3} \mathrm{O}_{4} / \mathrm{TiO}_{2}-\mathrm{S}$}

The suspension of $\mathrm{Fe}_{3} \mathrm{O}_{4}$ particles $(116 \mathrm{mg})$ and $\left(\mathrm{NH}_{4}\right)_{2} \mathrm{SO}_{4}(100 \mathrm{mg})$ in $20 \mathrm{~mL}$ of ethanol was sonicated for $10 \mathrm{~min}$. Then, titanium tetraisopropoxide with the optimum molar ratio of $\mathrm{Fe}_{3} \mathrm{O}_{4}$ : $\mathrm{TiO}_{2}$ and distilled water was introduced to the suspension, followed by the addition of the thiourea solution $\mathrm{S} \mathrm{TiO}_{2}$ molar ratios of $1,2,5,10$, and $15 \%$ ). The suspension was further sonicated for $3 \mathrm{~h}$. The precipitate was washed with distilled water, dried, and calcined at a temperature of $500{ }^{\circ} \mathrm{C}$ for $3 \mathrm{~h}$.

\section{Photocatalytic Experiment \\ Photoactivity of $\mathrm{Fe}_{3} \mathrm{O}_{4} / \mathrm{TiO}_{2}$}

The photocatalytic experiment was conducted under the stirring condition in a closed vessel equipped with a UV and a visible lamp. As much as $25 \mathrm{~mL}$ of a Congo red solution $(20 \mathrm{mg} / \mathrm{L})$ and $10 \mathrm{mg}$ of $\mathrm{Fe}_{3} \mathrm{O}_{4} / \mathrm{TiO}_{2}$ photocatalyst were placed in the glass vessel. The vessel was then irradiated at certain $\mathrm{pH}(3,4,5,6,7$, and 8 ) and for a certain irradiation time $(0,30,60,90,120$, and $180 \mathrm{~min})$. The photocatalyst was separated using an external magnet and the filtrate was analyzed using a UV-Vis spectrophotometer at $497 \mathrm{~nm}$. The degradation yield of Congo red was calculated using Eq.-1.

$$
\% \text { Degradation }=\frac{\mathrm{C}_{\mathrm{i}}-\mathrm{C}_{\mathrm{f}}}{\mathrm{C}_{\mathrm{i}}} \times 100 \%
$$

Where, $\mathrm{C}_{\mathrm{i}}(\mathrm{ppm})$ and $\mathrm{C}_{\mathrm{f}}(\mathrm{ppm})$ are the concentration of Congo red before and after the photocatalytic experiment. 
RASĀYAN J. Chem.

Vol. 14 | No. 2 |1199-1207| April - June | 2021

\section{Effect of Dopants on the Photoactivity of $\mathrm{Fe}_{3} \mathrm{O}_{4} / \mathrm{TiO}_{2}-\mathrm{S}$}

As much as $20 \mathrm{mg}$ of $\mathrm{Fe}_{3} \mathrm{O}_{4} / \mathrm{TiO}_{2}-\mathrm{S}$ (with the dopant concentration of $0,1,2,5,10$, and $15 \%$ ) was introduced to $25 \mathrm{~mL}$ of Congo red solution $(20 \mathrm{mg} / \mathrm{L})$ at a $\mathrm{pH} 5$. The photocatalytic degradation was performed for 90 min under UV and visible irradiation. After the process, the photocatalyst was separated and the filtrate was analyzed by a UV-visible spectrophotometer. The photocatalytic activity was evaluated using \% degradation of Congo red based on Eq.-1.

\section{Preparation of Photocatalysts}

\section{RESULTS AND DISCUSSION}

Our endeavor was started by preparing two types of photocatalysts including sulfur-undoped- and dopedtitania coated on magnetic. The first catalyst $\left(\mathrm{Fe}_{3} \mathrm{O}_{4} / \mathrm{TiO}_{2}\right)$ was prepared by coating $\mathrm{TiO}_{2}$ on $\mathrm{Fe}_{3} \mathrm{O}_{4}$ surface with a variation of molar ratio of $\mathrm{Fe}_{3} \mathrm{O}_{4}$ to $\mathrm{TiO}_{2}$. The catalyst which provides the best magnetic property and high content of titania will be then doped with sulfur. The sulfur-doped-catalyst $\left(\mathrm{Fe}_{3} \mathrm{O}_{4} / \mathrm{TiO}_{2}-\mathrm{S}\right)$ was produced by varying the concentration of sulfur dopant.

Figure-1 shows the XRD pattern as the function of the molar ratio of $\mathrm{Fe}_{3} \mathrm{O}_{4}$ to $\mathrm{TiO}_{2}$. The increase of $\mathrm{TiO}_{2}$ concentration (Fig.-1) allows the increase of the intensity of the peaks at $25^{\circ}, 38^{\circ}, 48^{\circ}$ and $53^{\circ}$, indicating that the anatase phase of $\mathrm{TiO}_{2}$ has been coated on the magnetite surface.

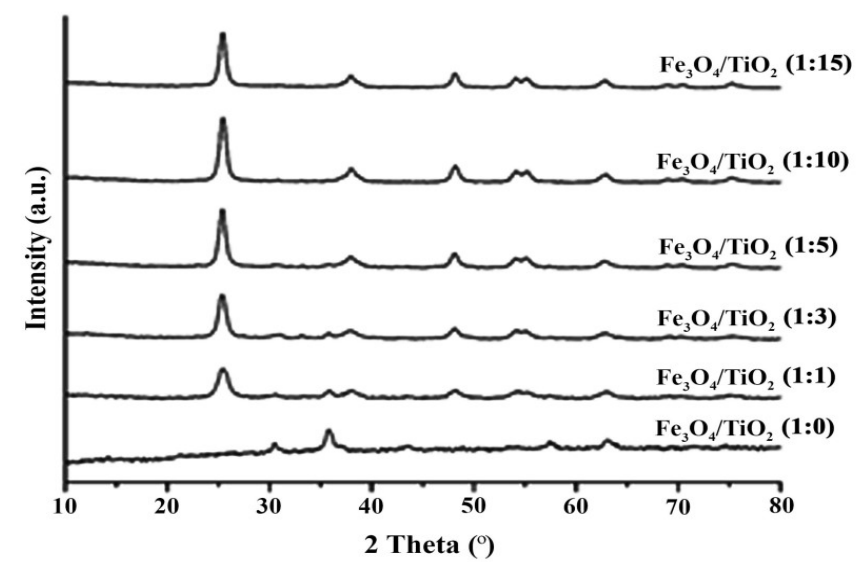

Fig.-1: XRD Pattern of $\mathrm{Fe}_{3} \mathrm{O}_{4} / \mathrm{TiO}_{2}$

Having prepared $\mathrm{Fe}_{3} \mathrm{O}_{4} / \mathrm{TiO}_{2}$ with different molar ratios, we then simply evaluated the magnetic properties of the photocatalysts by determining the mass of photocatalyst attracted by the external magnet. Table-1 (entry 1-3) demonstrates that increasing the molar ratio of titania up to 1:5 does not change the magnetic property of the photocatalyst. However, further addition of titania (Table-1, entry 4-5) will, indeed, cover the surface of magnetite and hence reduce the number of photocatalysts attracted to the external magnet, which is not suitable in the magnetically photodegradation study. Therefore, the molar ratio $\mathrm{Fe}_{3} \mathrm{O}_{4}: \mathrm{TiO}_{2}$ of 1:5 will be then used to synthesize the sulfur-doped-photocatalyst $\left(\mathrm{Fe}_{3} \mathrm{O}_{4} / \mathrm{TiO}_{2}-\mathrm{S}\right)$.

Table-1: The \% Magnetic attracted Mass of $\mathrm{Fe}_{3} \mathrm{O}_{4} / \mathrm{TiO}_{2}$ Photocatalyst with Different Molar Ratio

\begin{tabular}{c|c|c}
\hline Entry & $\mathrm{Fe}_{3} \mathrm{O}_{4}: \mathrm{TiO}_{2}$ & Magnetic Attraction (\%) \\
\hline 1 & $1: 1$ & 100 \\
\hline 2 & $1: 3$ & 100 \\
\hline 3 & $1: 5$ & 100 \\
\hline 4 & $1: 10$ & 94 \\
\hline 5 & $1: 15$ & 17 \\
\hline
\end{tabular}

The synthesis of sulfur-doped-titania coated on magnetite $\left(\mathrm{Fe}_{3} \mathrm{O}_{4} / \mathrm{TiO}_{2}-\mathrm{S}\right)$ was carried out using a similar method to that of $\mathrm{Fe}_{3} \mathrm{O}_{4} / \mathrm{TiO}_{2}$ photocatalyst. In this context, thiourea was employed as the source of sulfur dopant with the molar ratio of $\mathrm{S}$ to $\mathrm{TiO}_{2}$ of $1 \%, 2 \%, 5 \%, 10 \%$, and $15 \%$. The doping of sulfur to $\mathrm{Fe}_{3} \mathrm{O}_{4} / \mathrm{TiO}_{2}$ is expected to give photocatalyst with good photoactivity and response to visible light. 
RASĀYAN J. Chem.

Vol. 14 | No. 2 |1199-1207| April - June | 2021

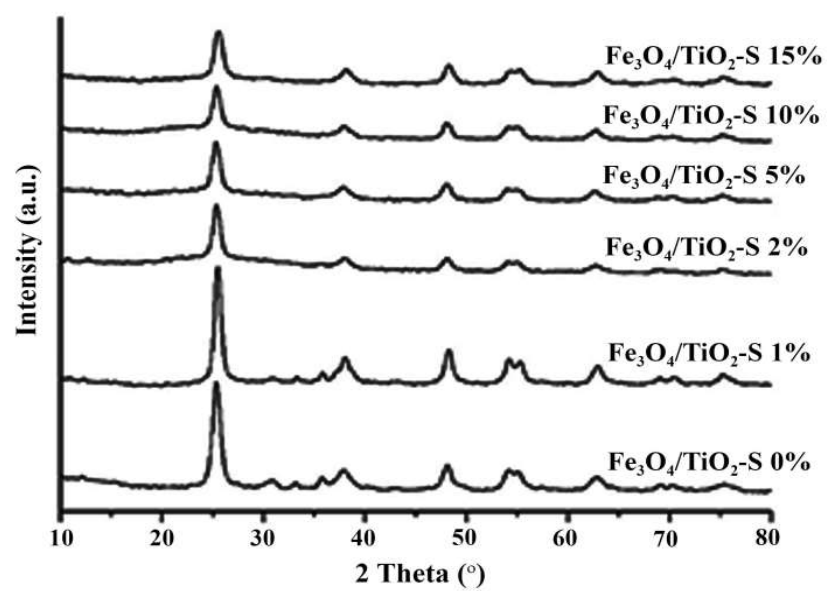

Fig.-2: Diffractogram of $\mathrm{Fe}_{3} \mathrm{O}_{4} / \mathrm{TiO}_{2}-\mathrm{S}$

Based on the XRD diffractogram of various $\mathrm{Fe}_{3} \mathrm{O}_{4} / \mathrm{TiO}_{2}-\mathrm{S}$ photocatalysts depicted in Fig.-2, the intensity of anatase $\mathrm{TiO}_{2}$ characteristic peaks $\left(25^{\circ}, 38^{\circ}, 48^{\circ}, 53^{\circ}, 62^{\circ}\right.$ and $\left.75^{\circ}\right)$ decrease along with the increase of sulfur dopant concentration, which indicates that the sulfur dopant enters the crystal lattice of $\mathrm{TiO}_{2}$. It should be also noted that the addition of dopant did not significantly damage the crystal structure of anatase $\mathrm{TiO}_{2}$. Compared with the non-doped photocatalyst, the sulfur-doped-photocatalysts $\mathrm{Fe}_{3} \mathrm{O}_{4} / \mathrm{TiO}_{2}-\mathrm{S}$ relatively give the lower intensity of peak at $3400 \mathrm{~cm}^{-1}$, indicating that hydroxyl group of titania is substituted with the sulfur group. The presence of sulfur in the photocatalyst is confirmed by the weak peak in around 1100$1040 \mathrm{~cm}^{-1}$ coming from the $\mathrm{S}-\mathrm{O}$ and $\mathrm{S}=\mathrm{O}$ bonds stretching vibration.

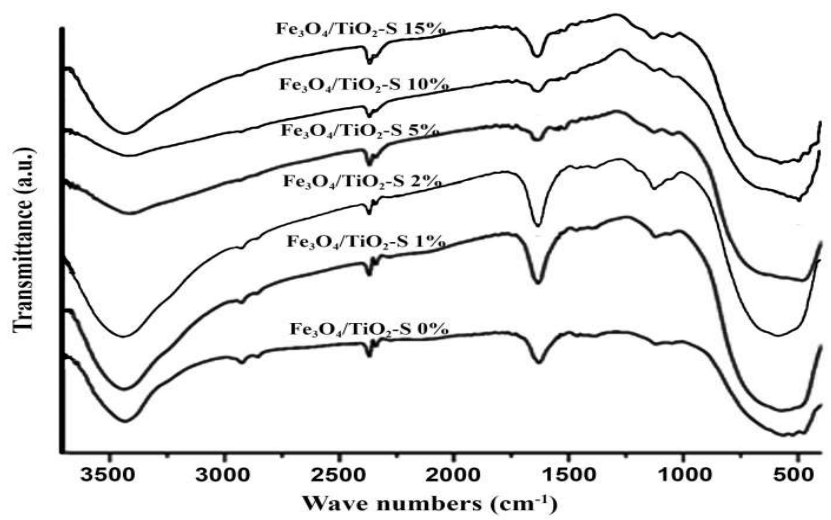

Fig.-3: FTIR Spectra of $\mathrm{Fe}_{3} \mathrm{O}_{4} / \mathrm{TiO}_{2}-\mathrm{S}$

The optical properties of the photocatalyst were determined using SR UV-Visible spectrophotometer (Fig.4). Table- 2 shows that the sulfur doping process may decrease the bandgap energy and increase the edge absorption wavelength (entry 2-6). This is probably because $\mathrm{S}^{4+}$ may enter the crystal lattice to replace $\mathrm{Ti}^{4+}$, hence more new energy levels are formed under the conduction band resulting in a narrower bandgap.

The increase of bandgap energy was observed when $15 \%$ of dopant was used (Table-2, entry 7 ). According to the Burstein-Moss effect ${ }^{19}$, the doping process will push the fermi level closer to the conduction band. With higher dopant concentration, the fermi level is pushed above the conduction band which has been filled with electrons due to the doping effect, so that the excited electrons will occupy the higher fermi level.

Evaluation of the optical properties using SR UV-Visible spectrophotometer shows that $\mathrm{Fe}_{3} \mathrm{O}_{4} / \mathrm{TiO}_{2}-\mathrm{S} 10 \%$ display the smallest bandgap energy of $3.05 \mathrm{eV}$. It is interesting to highlight that the doping shifts the edge absorption wavelength to the visible light region, i.e., $407 \mathrm{~nm}$. Therefore, the photocatalyst of $\mathrm{Fe}_{3} \mathrm{O}_{4} / \mathrm{TiO}_{2-}$ S $10 \%$ will be employed in the photocatalytic experiment. 
RASĀYAN J. Chem.

Vol. 14 | No. 2 |1199-1207| April - June | 2021

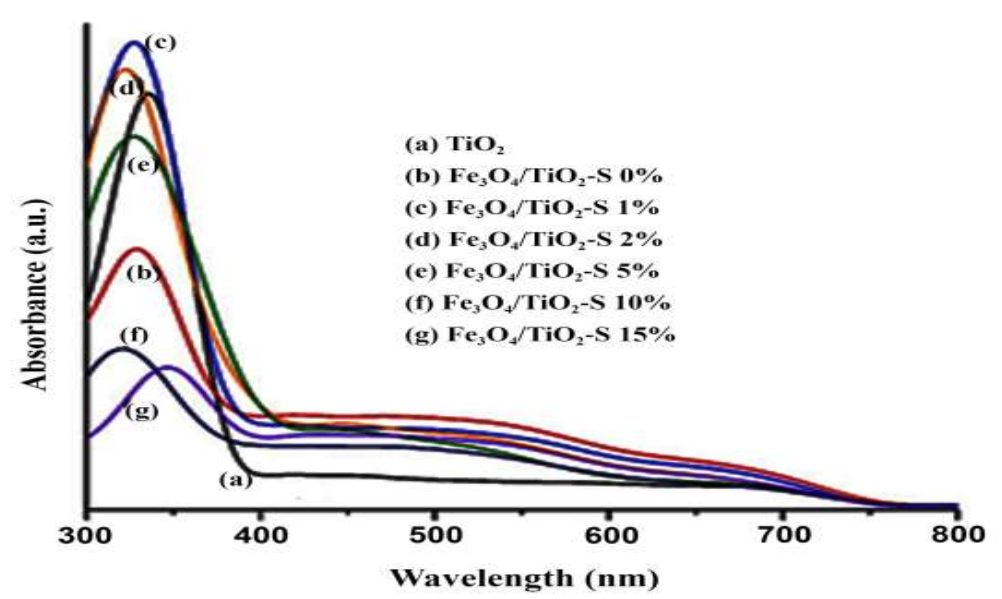

Fig.-4: SR UV-Visible Spectra of $\mathrm{TiO}_{2}$ and $\mathrm{Fe}_{3} \mathrm{O}_{4} / \mathrm{TiO}_{2}-\mathrm{S}$

Table-2: The Photocatalyst Bandgap Energy

\begin{tabular}{c|c|c|c}
\hline Entry & Photocatalyst & Energy of Bandgap (eV) & Wavelength (nm) \\
\hline 1 & $\mathrm{TiO}_{2}$ & 3.27 & 380 \\
\hline 2 & $\mathrm{Fe}_{3} \mathrm{O}_{4} / \mathrm{TiO}_{2}$ & 3.22 & 386 \\
\hline 3 & $\mathrm{Fe}_{3} \mathrm{O}_{4} / \mathrm{TiO}_{2}-\mathrm{S} \mathrm{1 \%}$ & 3.23 & 385 \\
\hline 4 & $\mathrm{Fe}_{3} \mathrm{O}_{4} / \mathrm{TiO}_{2}-\mathrm{S} \%$ & 3.10 & 400 \\
\hline 5 & $\mathrm{Fe}_{3} \mathrm{O}_{4} / \mathrm{TiO}_{2}-\mathrm{S} \mathrm{5 \%}$ & 3.08 & 403 \\
\hline 6 & $\mathrm{Fe}_{3} \mathrm{O}_{4} / \mathrm{TiO}_{2}-\mathrm{S} \mathrm{10 \%}$ & 3.05 & 407 \\
\hline 7 & $\mathrm{Fe}_{3} \mathrm{O}_{4} / \mathrm{TiO}_{2}-\mathrm{S} \mathrm{15 \%}$ & 3.34 & 371 \\
\hline
\end{tabular}

The morphology of the photocatalyst was investigated using TEM as displayed in Fig.-5. It is found that both photocatalysts $\left(\mathrm{Fe}_{3} \mathrm{O}_{4} / \mathrm{TiO}_{2} 1: 5\right.$ and $\left.\mathrm{Fe}_{3} \mathrm{O}_{4} / \mathrm{TiO}_{2}-\mathrm{S} 10 \%\right)$ have the core-shell structure as indicated from the shape of the particles, which are spherical and black, covered in gray. While the black particle represents $\mathrm{Fe}_{3} \mathrm{O}_{4}$, the gray particle shows the presence of $\mathrm{TiO}_{2}$. The TEM images also show that the sulfur dopants do not significantly change the shape and size of the material.

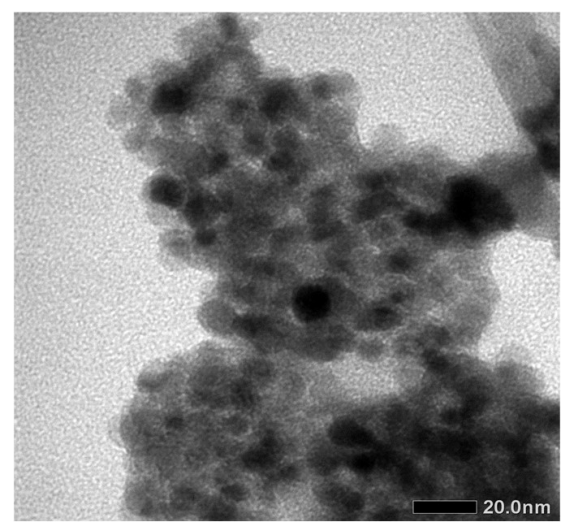

(a)

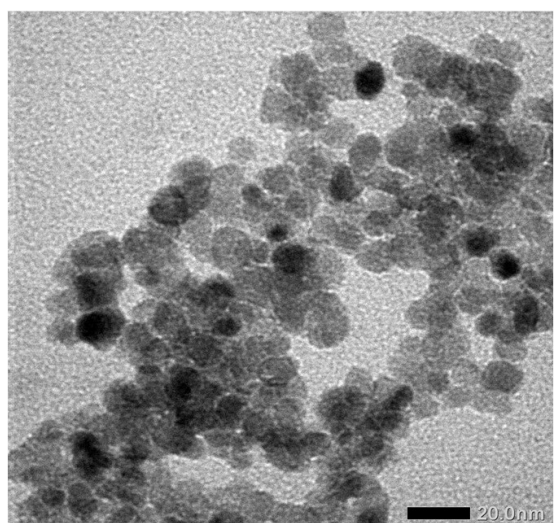

(b)

Fig.-5: TEM images of $\mathrm{Fe}_{3} \mathrm{O}_{4} / \mathrm{TiO}_{2}$ 1:5 (a) dan $\mathrm{Fe}_{3} \mathrm{O}_{4} / \mathrm{TiO}_{2}-\mathrm{S} 10 \%$ (b)

Based on the EDX spectrum (Fig.-6), the elements on the surface of the material include O, Ti, Fe, and S. Oxygen appears as the most abundant atom in the material since it binds both $\mathrm{Ti}$ and $\mathrm{Fe}$ atoms in the photocatalysts. Indeed, the order of atom composition of the rest atoms $(\mathrm{Ti}>\mathrm{Fe}>\mathrm{S})$ (Table-3) can be explained from the molar ratio used in the preparation of the photocatalyst. These results also indicate that the sulfur doping of the material was successfully performed without other impurities. 
RASĀYAN J. Chem.

Vol. 14 | No. 2 |1199-1207| April - June | 2021

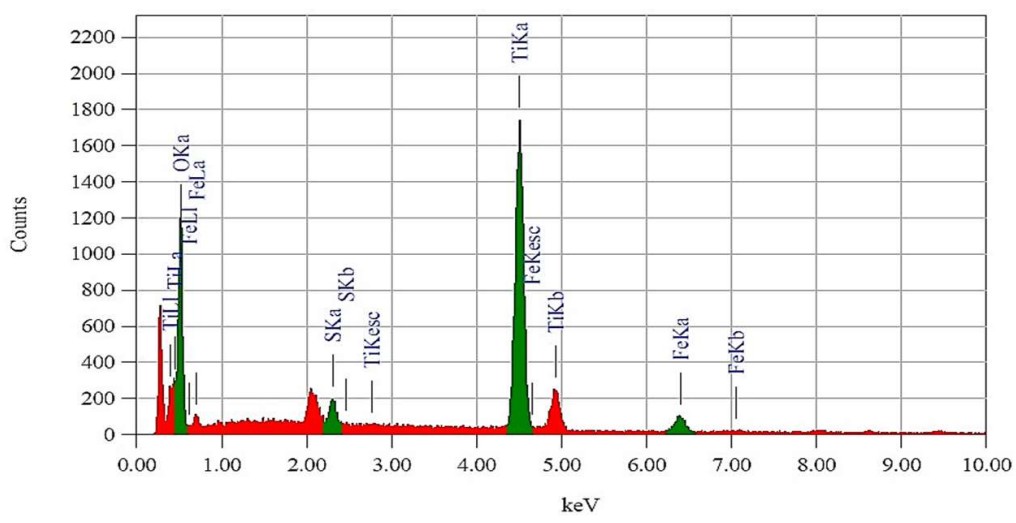

Fig.-6: The EDX Spectrum of $\mathrm{Fe}_{3} \mathrm{O}_{4} / \mathrm{TiO}_{2}-\mathrm{S} 10 \%$

Table-3: Composition of Elements on the Surface of $\mathrm{Fe}_{3} \mathrm{O}_{4} / \mathrm{TiO}_{2}-\mathrm{S} 10 \%$

\begin{tabular}{c|c|c|c}
\hline Entry & Element & $\%$ Mass & \% Atom \\
\hline 1 & $\mathrm{O}$ & 50.27 & 75.18 \\
\hline 2 & $\mathrm{~S}$ & 1.44 & 1.07 \\
\hline 3 & $\mathrm{Ti}$ & 43.06 & 21.51 \\
\hline 4 & $\mathrm{Fe}$ & 5.23 & 2.24 \\
\hline
\end{tabular}

The vibrating sample magnetometer (VSM) analysis was then carried out to determine the magnetization of the photocatalyst. Results show that there is a decline in the magnetic properties of $\mathrm{Fe}_{3} \mathrm{O}_{4}$ after coating with $\mathrm{TiO}_{2}$ (Fig.-7). It is indicated that $\mathrm{TiO}_{2}$ well coats the $\mathrm{Fe}_{3} \mathrm{O}_{4}$ particles. The reduction in the magnetic moment (M) of $\mathrm{Fe}_{3} \mathrm{O}_{4} / \mathrm{TiO}_{2}-\mathrm{S}$ nanoparticles is also observed (Table-4).

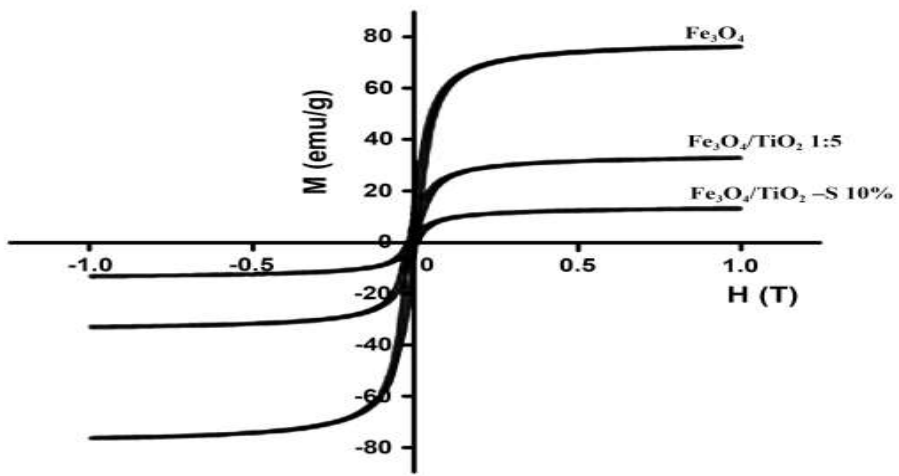

Fig.-7: VSM Curve of $\mathrm{Fe}_{3} \mathrm{O}_{4}, \mathrm{Fe}_{3} \mathrm{O}_{4} / \mathrm{TiO}_{2} 1: 5$ and $\mathrm{Fe}_{3} \mathrm{O}_{4} / \mathrm{TiO}_{2}-\mathrm{S} 10 \%$

Table-4: Magnetic Property of $\mathrm{Fe}_{3} \mathrm{O}_{4}, \mathrm{Fe}_{3} \mathrm{O}_{4} / \mathrm{TiO}_{2}$, and $\mathrm{Fe}_{3} \mathrm{O}_{4} / \mathrm{TiO}_{2}-\mathrm{S}$

\begin{tabular}{c|c|c}
\hline Entry & Material & $\mathrm{M}(\mathrm{emu} / \mathrm{g})$ \\
\hline 1 & $\mathrm{Fe}_{3} \mathrm{O}_{4}$ & 76.03 \\
\hline 2 & $\mathrm{Fe}_{3} \mathrm{O}_{4} / \mathrm{TiO}_{2} 1: 5$ & 32.80 \\
\hline 3 & $\mathrm{Fe}_{3} \mathrm{O}_{4} / \mathrm{TiO}_{2}-\mathrm{S} 10 \%$ & 13.15 \\
\hline
\end{tabular}

\section{Photocatalytic Experiment}

The photocatalytic activity of the sulfur-doped-titania coated on magnetite photocatalysts is investigated by degradation of an anionic azo dye, namely Congo red, in an aqueous solution under UV and visible irradiation. After the experiment, the photocatalyst can be easily separated using the external magnet. The remaining solution was then analyzed using a UV-Vis spectrophotometer at $497 \mathrm{~nm}$. The photoactivity of the catalyst can be represented by \% degradation of the dye (Eq.-1). Initially, we evaluated the effect of solution of $\mathrm{pH}$ and degradation time on the \% degradation of Congo red using $\mathrm{Fe}_{3} \mathrm{O}_{4} / \mathrm{TiO}_{2}$ 1:5 photocatalyst. Once the optimum conditions are obtained, we employed various $\mathrm{Fe}_{3} \mathrm{O}_{4} / \mathrm{TiO}_{2}-\mathrm{S}$ in the photocatalytic experiment under the exposure of UV and visible light. 
RASĀYAN J. Chem.

Vol. 14 | No. 2 |1199-1207| April - June | 2021

\section{Effect of pH on the Photodegradation of Congo Red}

The photocatalytic study reveals that the degradation of Congo red using $\mathrm{Fe}_{3} \mathrm{O}_{4} / \mathrm{TiO}_{2}$ 1:5 photocatalyst is pH-dependent. As depicted in Fig.-8, a high \% degradation (88.42\%) is obtained when the photodegradation is conducted at $\mathrm{pH} 3$. The degradation efficiency slightly increases and reaches the optimum point at $\mathrm{pH} 5$ $(91.67 \%)$. Increasing the solution $\mathrm{pH}$ leads to the decrease of \% degradation of Congo red. The phenomena can be explained by considering the species of both $\mathrm{TiO}_{2}$ and Congo red in an aqueous solution under different $\mathrm{pH}$ values.

The $\mathrm{TiO}_{2}$ surface will be protonated to give $\mathrm{TiOH}_{2}{ }^{+}$in the acidic condition (less than $\mathrm{pH}$ 6). On the other hand, Congo red (pKa 4.1) will exist as its anionic form along with the increasing of $\mathrm{pH}$. Therefore, the optimum $\mathrm{pH}$ was obtained at $\mathrm{pH} 5$, where the electrostatic interaction between positively-chargedphotocatalyst and anionic Congo red may optimally occur and may subsequently induce the photodegradation of the dye. Further increase of the solution $\mathrm{pH}(\mathrm{pH} \mathrm{6-8)}$ will generate the negativelycharged- $\mathrm{TiO}_{2}$ surface $\left(\mathrm{TiO}^{-}\right)$. As the consequence, there will be a repulsion interaction between these two anionic species, leading to the decrease of the \% degradation of Congo red. Based on the previous explanation, the optimum $\mathrm{pH}$ of the $\mathrm{Fe}_{3} \mathrm{O}_{4} / \mathrm{TiO}_{2}$-catalyzed-degradation of Congo red is $\mathrm{pH}$ 5. From the operational point of view, this condition is not relatively extreme for wastewater treatment.

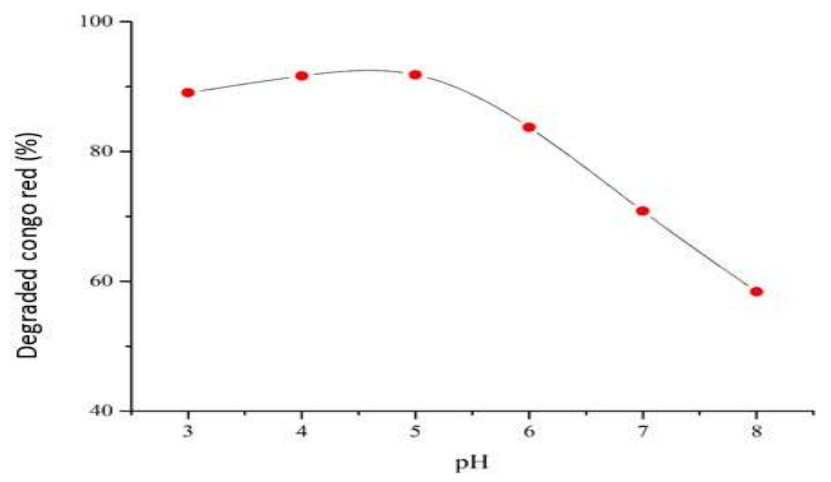

Fig.-8: Effect of $\mathrm{pH}$ on the Photodegradation of Congo Red catalyzed by $\mathrm{Fe}_{3} \mathrm{O}_{4} / \mathrm{TiO}_{2} 1: 5$

\section{Effect of Interaction Time on the Photodegradation of Congo Red}

Interaction time is one of the important factors in wastewater treatment. In this context, the photoactivity of $\mathrm{Fe}_{3} \mathrm{O}_{4} / \mathrm{TiO}_{2}$ in the degradation of Congo red significantly increases during the first 60 min and reaches the optimum point at $90 \mathrm{~min}$. The constant degradation percentage is observed as the optimum interaction time (Fig.-9). The longer irradiation time allows the generation of a higher amount of $\mathrm{O}_{2} \bullet^{-}$and $\mathrm{OH} \bullet$ as the active species in the photodegradation of Congo red. It is interesting to note that, more than $90 \%$ of Congo red dye photodegraded using $\mathrm{Fe}_{3} \mathrm{O}_{4} / \mathrm{TiO}_{2}$ photocatalyst.

Figure- 8 indicates that the longer the irradiation time in the photodegradation process, the greater the percentage of degradation. This is because of the longer contact time between the photocatalyst material and the Congo red molecule. The longer the irradiation time, the more radicals $\mathrm{O}_{2} \bullet^{-}$and $\mathrm{OH} \bullet$ degrade the dye molecules. This figure shows that the optimum irradiation time is 90 minutes. The degradation percentages at 120 and 180 minutes were relatively constant. After 90 minutes of irradiation, the number of electrons and holes generated in $\mathrm{TiO}_{2}$ did not increase significantly so the percent degradation did not increase significantly.

\section{Effect of Sulfur on the Photoactivity of $\mathrm{Fe}_{3} \mathrm{O}_{4} / \mathrm{TiO}_{2}-\mathrm{S}$}

With the optimum photodegradation conditions in our hand, we then turned our attention to study the effect of dopant concentration. We found that both the coating process on magnetite and the sulfur doping strategy may improve the performance of $\mathrm{TiO}_{2}$ in the Congo red photodegradation underexposure of either UV or visible light (Fig.-10). The presence of magnetite may enhance the interaction between the photocatalyst and substrate, hence, improve the effectiveness of the coated photocatalysts. In addition, under visible light irradiation, we found that the unmodified $\mathrm{TiO}_{2}$ photocatalyst display low photoactivity which is presumably due to the high band gap energy of $\mathrm{TiO}_{2}$. 
RASĀYAN J. Chem.

Vol. 14 | No. 2 |1199-1207| April - June | 2021

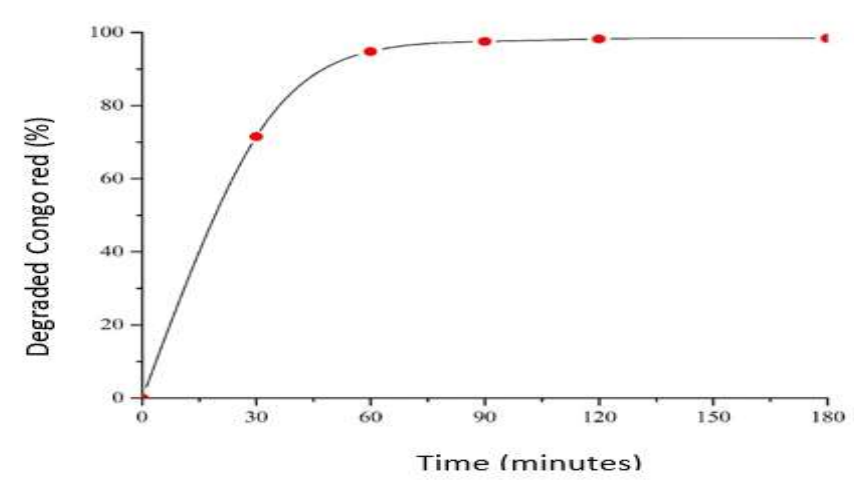

Fig.-9: Effect of Time on the Photodegradation of Congo Red catalyzed by $\mathrm{Fe}_{3} \mathrm{O}_{4} / \mathrm{TiO}_{2}$

As displayed in Fig.-10, all $\mathrm{Fe}_{3} \mathrm{O}_{4} / \mathrm{TiO}_{2}-\mathrm{S}$ photocatalysts $(0-15 \% \mathrm{~S})$ give excellent photodegradation percentage (more than $85 \%$ ) when the experiment is conducted under the exposure of UV light. Indeed, the UV light provides the excess energy to catalyze the photodegradation via the electron excitation from the valence to the conduction band.

To our delight, the sulfur doping technique allows us to enlarge the application of the photocatalyst for photodegradation under the visible light region. In general, the photodegradation activity is related to the catalyst band gap energy (Table-2). As previously explained, the presence of sulfur dopant on the magnetite-coated-titania may narrow the bandgap energy since a new energy level was generated below the conduction band. Therefore, energy provided by visible light is sufficient to promote the excitation of electrons in the photocatalytic process. Additionally, the edge absorption band might be shifted to the visible light region.

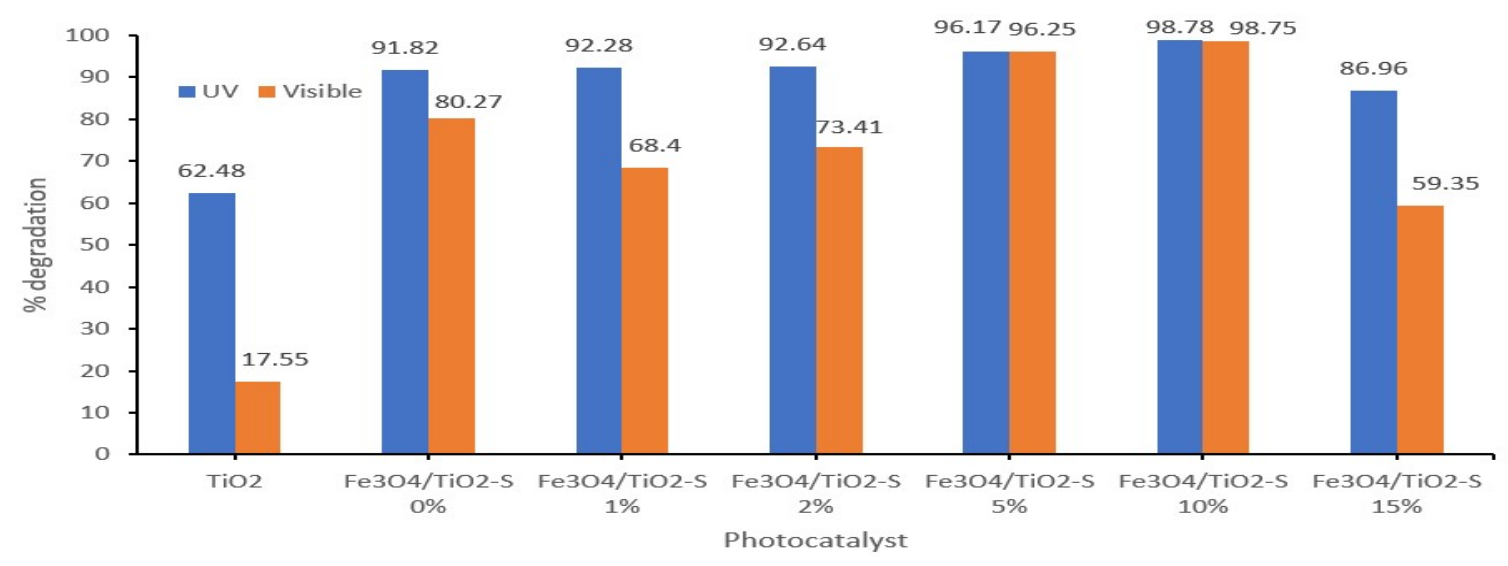

Fig.-10: Degradation of Congo Red catalyzed by $\mathrm{Fe}_{3} \mathrm{O}_{4} / \mathrm{TiO}_{2}-\mathrm{S}$ Photocatalysts

It should be noted that both $\mathrm{Fe}_{3} \mathrm{O}_{4} / \mathrm{TiO}_{2}-\mathrm{S} 5 \%(3.08 \mathrm{eV}, 403 \mathrm{~nm})$ and $10 \%(3.05 \mathrm{eV}, 407 \mathrm{~nm})$ catalysts show excellent performance in the degradation of Congo red with the photoactivity of $96.25 \%$ and $98.75 \%$, respectively (Fig.-10). It is apparent that the lower the bandgap energy (Table-2), the more efficient the system in generating the active species of $\mathrm{O}_{2} \bullet^{-}$and $\mathrm{OH} \bullet$ radicals for the degradation of Congo red.

\section{CONCLUSION}

The magnetically recoverable sulfur-doped-titania coated on magnetite $\left(\mathrm{Fe}_{3} \mathrm{O}_{4} / \mathrm{TiO}_{2}-\mathrm{S}\right)$ photocatalysts have been successfully synthesized by facile sono-coprecipitation method and dispersion with ethanol followed by thermal treatment, where thiourea is employed as the source of sulfur dopant. The sulfur doping strategy allows us to obtain the photocatalysts with lower bandgap energy and shift the edge absorption band to the visible light wavelength. More importantly, we succeed to conduct the photodegradation of Congo red at $\mathrm{pH} 5$ for 90 min under the illumination of UV and visible light. The $\mathrm{Fe}_{3} \mathrm{O}_{4} / \mathrm{TiO}_{2}-\mathrm{S}$ photocatalysts also display good magnetic properties and can be recovered from the liquid medium by simply using the external 
RASĀYAN J. Chem.

Vol. 14 | No. 2 |1199-1207| April - June | 2021

magnetic field. The results demonstrate that both $\mathrm{Fe}_{3} \mathrm{O}_{4} / \mathrm{TiO}_{2}-\mathrm{S} 5 \%$ and $10 \%$ photocatalysts are very active for the visible light-promoted-photodegradation of Congo red with the photoactivity of $96.25 \%$ and $98.75 \%$, respectively. The photodegradation study of Congo red using the magnetically recoverable sulfurdoped-titania coated on magnetite $\left(\mathrm{Fe}_{3} \mathrm{O}_{4} / \mathrm{TiO}_{2}-\mathrm{S}\right)$ under sunlight illumination is underway.

\section{ACKNOWLEDGEMENT}

The authors gratefully acknowledge the financial support from The Directorate General of Higher Education, Ministry of Research Technology and the Higher Education Republic of Indonesia, and Universitas Gadjah Mada through the PDUPT 2020 grant (No.6/AMD/E1/KP.PTNBH/2020 and 2771/UN1/DITLIT/DIT-LIT/PT/2020).

\section{REFERENCES}

1. Y. Shen, T. Xiong, H. Du, H. Jin, J. Shang and K. Yang, Journal of Sol-Gel Science and Technology, 50(1), 98(2009), DOI:10.1007/s10971-009-1903-8

2. R. Qiu, D. Zhang, Z. Diao, X. Huang, C. He, J.L. Morel and Y. Xiong, Water Research, 46 (7), 2299(2012), DOI:10.1016/j.watres.2012.01.046

3. C. Xu, G.P. Rangaiah and X.S. Zhao, Industrial \& Engineering Chemical Research, 53 (38), 14641(2014), DOI:10.1021/ie502367x

4. E.S. Kunarti, A. Syoufian, I.S. Budi and A.R. Pradipta, Asian Journal of Chemistry, 28 (6), 1343(2016), DOI:10.14233/ajchem.2016.19697

5. C. Han, M. Pelaez, V. Likodimos, A.G. Kontos, P. Falaras, K. O'Shea and D.D. Dionysiou, Applied Catalysis B Environmental, 107, 77(2011), DOI:10.1016/j.apcatb.2011.06.039

6. S.G. Kumar and L.G. Devi, Journal of Physical Chemistry, 115, 13211(2011), DOI: $10.1021 /$ jp204364a

7. K. Melghit, O.S. Al-shukeili and I. Al-Amri, Ceramics International, 35, 433(2009), DOI: 10.1016/j.ceramint.2007.12.009

8. J.V. Morin, E.T. Wahyuni, A. Suratman and A. Ashari, Rasayan Journal of Chemistry, 13 (2), 1225(2020), DOI: 10.31788/RJC.2020.1325720

9. P. Periyat, S.C. Pillai, D.E. Mccormack, J. Colreavy and S.J. Hinder, Journal of Physical Chemistry C.,112, 7644(2008), DOI:10.1021/jp0774847

10. Ardiansyah, I.E. Purba, M. Tarigan, Lisnadiyanti, Yusnaidar and I.P. Mahendra, Rasayan Journal of Chemistry, 13(1), 757(2020), DOI:10.31788/RJC.2020.1315461

11. S. Sun, J. Zhang, P. Gao, Y. Wang, X. Li, T. Wu, Y. Wang, Y. Chen and P. Yang, Applied Catalysis B, Environmental, 206, 168(2017), DOI:10.1016/j.apcatb.2017.01.027

12. M. Pelaez, A.A. de la Cruz, E. Stathatos, P. Falaras and D.D Dionysiou, Catalysis Today, 144, 19(2009), DOI:10.1016/j.cattod.2008.12.022

13. X. Chen, D.H. Kuo and D. Lu, Advanced Powder Technology, 28, 1213(2017), DOI:10.1016/j.apt.2017.02.007

14. X-Q. Chen, H-X Zhang and W-H Shen, Materials Chemistry and Physics, 216, 496(2018), DOI: $10.1016 /$ j.matchemphys.2018.06.037

15. E.S. Kunarti, I. Kartini, A. Syoufian and K.M. Widyandari, Indonesian Journal of Chemistry, 18(3), 403(2018), DOI: $10.22146 /$ ijc.26831

16. F.C. Nalle, R.Wahid, I.O Wulandari and A. Sabarudin, Rasayan Journal of Chemistry, 12(1), 14(2019), DOI: $10.31788 /$ RJC.2019.1214082

17. V.C. Nguyen, T.Q. Hieu and L.D. Vu, Rasayan Journal of Chemistry, 10(4), 1446(2017), DOI: $10.7324 /$ RJC.2017.1041894

18. I. S. Budi, S. J. Santosa and E. S. Kunarti, Rasayan Journal of Chemistry, 13(1), 202(2020), DOI: $10.31788 /$ RJC.2020.1315509

19. S.N. Svitasheva and A.M. Gilinsky, Applied Surface Science, 281, 109(2013), DOI:10.1016/j.apsusc.2013.02.094

[RJC-6304/2020] 